\title{
Characterization and Identification of DUS Traits in Reference Set of Foxtail Millet Germplasm (Setaria italica (L.) Beauv.)
}

\author{
Harshiya Banu ${ }^{*}$, Jayarame Gowda ${ }^{2}$ and M. V. Channabyre Gowda ${ }^{2}$ \\ ${ }^{1}$ AICRP on Sesame and Niger, MARS, University of Agricultural Sciences, Dharwad, \\ Karnataka, India \\ ${ }^{2}$ Project Co-ordinating Unit (Small millets), University of Agricultural Sciences, Gandhi \\ Krishi Vignana Kendra,Bangalore, Karnataka-560065, India
}

*Corresponding author

\begin{tabular}{|l|}
\hline Ke y w o r d s \\
Reference set, \\
Germplasm, Qualitative \\
characters, \\
Characterization, DUS \\
test
\end{tabular}

\section{Introduction}

Foxtail millet is one of the world's oldest cultivated crop belongs to the grass family Poaceae. Foxtail millet ranks second in the total world's production of millets and is an important staple food for millions of people in
Southern Europe and Asia (Marathee, 1993). Qualitative characters are useful criterion for characterization of group of materials, as they show high heritability and stable expression. Further, if qualitative characters show association with yield components, it can serve as a marker in selection process which 
are less influenced by environmental fluctuations. Qualitative traits are easily scorable/assayable, show simple inheritance (single/oligogenic) and stable expression, and selectively neutral (Smith and Smith, 1992), they serve as diagnostic descriptors of germplasm accessions and hence useful to avoid mistakes in labelling, aid identification and minimize duplication in the germplasm and helps easy retrieval of desired accessions from the germplasm database. Qualitative traits polymorphism has been attributed to diversity in phylogeny (Noirot et al., 1996). Characterization should eventually lead to a system of recording and storing useful data that can be readily retrieved and made available to others and help in planning breeding programmes (Debas et al., 1994). Germplasm forms the raw material for any crop improvement program. There is wide genetic diversity available in foxtail millet and characterizing these resources is a prerequisite for the genetic improvement of its cultivars.

The characterization and evaluation are the important pre requisites for effective utilization of germplasm and also to identify sources of useful genes (Upadhayay et al., 2010). Characterization of germplasm is useful to identify and avoid duplication. Qualitative traits being more stable over generations (Raut, 2003) hence are reliable for characterization of germplasm/varieties. Systematic study and characterization of such germplasm is not only important for utilizing the appropriate attribute based donors, but also essential in the present era for protecting the unique foxtail millet. Thus, there is a need to collect, exploit, and evaluate the untapped germplasm. In this context, an attempt was made to characterize a set of foxtail millet germplasm for different morphological traits and identify the variability available in the collection. Keeping in view of these facts, the present investigation was planned to characterize a reference set of foxtail millet in order to understand the qualitative differentiation for Distinct, Unique and Stable traits to reduce redundancy.

\section{Materials and Methods}

The material for the present investigations consisted of two hundred and twenty three germplasm accessions including core set, trait specific accessions and all the released varieties in the country along with 3 National check varieties (SiA 326, SiA 3085 and PS 4) represented as reference set which includes extensive collections from various parts of world maintained at National

Active Germplasm Collection Site (NAGS) were characterized into four groups viz., growth, leaf, floral and grain traits with respect to growth habit, sheath pubescence, blade pubescence, auricle pigmentation, leaf attitude, inflorescence pigmentation, anther pigmentation, inflorescence bristles, inflorescence compactness, inflorescence lobes, lobe compactness, inflorescence shape, plant pigmentation at maturity, apical sterility, grain colour and grain shape using 16 qualitative traits which were identified as Distinctiveness, Uniformity and Stability (DUS) test. The material was grown in augmented design during Kharif 2012 at experimental plots of Project Coordinating Unit (small millets), Zonal Agricultural Research Station, University of Agricultural Sciences, GKVK, Bangalore which is located at an altitude of $930 \mathrm{~m}$ above mean sea level $13^{\circ} 05^{\prime}$ North and $77^{\circ} 35^{\prime}$ East latitude and longitude, respectively. Each accession was grown in a single row of $3 \mathrm{~m}$ length with a spacing of $30 \mathrm{~cm}$ between rows and $10 \mathrm{~cm}$ between plants within a row $(30 \mathrm{~cm} \mathrm{X} 10 \mathrm{~cm})$ for characterization of reference set at different stages of crop growth was carried out. Observations were recorded on five randomly chosen plants of each accession for growth, leaf, floral and grain traits. The 
reference set germplasm were characterized based on the descriptors of Setaria italica and S. pumila (IBPGR, 1985) and by using evaluation of foxtail millet germplasm catalogue developed by Project Coordinating Unit (Small millets), UAS, GKVK, Bangalore 2002. Based on morphologically distinct features, a visual scoring were recorded for qualitative characters. Frequency distributions for all the qualitative traits were computed using statistical analysis SPSS version 20.0 software.

\section{Results and Discussion}

The reference set germplasm under study showed wide range of variability for all the qualitative traits studied. Sixteen qualitative traits were recorded for two hundred and twenty three accessions. Frequency distribution of different qualitative traits revealed large variation for each trait. The accessions were based on the variability present in each one of the qualitative traits under different sub descriptors. The results for each trait are described briefly is presented in Table 1 and its graphical representation is shown in Figure 1. Characterization at different growth stages of crop were discussed below.

\section{Growth traits}

Depending on the growth habit of foxtail millet, the accessions were classified into erect, erect geniculate, decumbent and prostrate were observed in evaluated germplasm accessions. Maximum number of 190 accessions (85.2 \%) showed erect type followed by erect geniculate (20 accessions and $9.0 \%$ ), decumbent (9 accessions and 4.0 $\%)$ and only 4 accessions $(1.8 \%)$ had prostrate growth habit. Similar findings have been reported in foxtail millet by Gopal Reddy et al., (2006) and Gopal Reddy et al., (2009) in finger millet.

\section{Leaf traits}

Regarding sheath pubescence, majority of accessions (111 accessions and $49.8 \%$ ) exhibited medium pubescent followed by essentially glaborous (100 accessions and 44.8 $\%)$, while 12 accessions (5.4\%) exhibited strongly pubescent. As many as 121 accessions (54.3\%) showed essentially glaborous blade pubescent followed by medium blade pubescent (88 accessions and $39.5 \%)$ and 14 accessions (6.3\%) had strongly blade pubescent, indicating pubescence is reported in effective for conferring resistance to insect pests in dolichos bean (Jagadeesh Babu et al., 2008). These findings are in consonance with those of Gopal Reddy et al., (2007) in proso millet germplasm. With respect to auricle pigmentation, accessions with non-pigmented auricle (197 accessions and $88.3 \%$ ) were more frequent compared to pigmented auricle (26 accessions and $11.7 \%$ ).

The present finding is in consonance with those of Gopal Reddy et al., (2006) in foxtail millet and Chandrashekhar Hardari (2009) in finger millet. Shigeta (1985) reported that high yield was associated with purple pigmentation in plant parts. Rao (1948) found that pigmented genotypes were more resistant to blast disease. Regarding leaf attitude, genotypes were more frequent (79 accessions and $35.4 \%$ ) towards drooping type than those bearing intermediate (73 accessions and 32.7 $\%$ ) and erect leaf attitude (71 accessions and $31.8 \%$ ). Similar finding was reported by Selvi et al., (2013) in maize.

\section{Floral traits}

The accessions with non-pigmented inflorescence were represented in higher frequency (194 accessions and $87.0 \%$ ) than those with pigmented inflorescence (29 accessions and $13.0 \%$ ). 
Table.1 Variability for qualitative traits and their frequency in reference set of foxtail millet

\begin{tabular}{|c|c|c|c|c|c|}
\hline Sl. No. & Descriptors & Score & Sub descriptors & Frequency & Percentage \\
\hline I & \multicolumn{5}{|c|}{ Growth traits } \\
\hline \multirow[t]{4}{*}{1} & \multirow[t]{4}{*}{ Growth habit } & 1 & Erect & 190 & 85.2 \\
\hline & & 2 & Erect geniculate & 20 & 9.0 \\
\hline & & 3 & Decumbent & 9 & 4.0 \\
\hline & & 4 & Prostrate & 4 & 1.8 \\
\hline II & \multicolumn{5}{|c|}{ Leaf traits } \\
\hline \multirow[t]{3}{*}{2} & \multirow[t]{3}{*}{ Sheath pubescence } & 1 & Essentially glaborous & 100 & 44.8 \\
\hline & & 5 & Medium pubescent & 111 & 49.8 \\
\hline & & 9 & Strongly pubescent & 12 & 5.4 \\
\hline \multirow[t]{3}{*}{3} & \multirow[t]{3}{*}{ Blade pubescence } & 1 & Essentially glaborous & 121 & 54.3 \\
\hline & & 5 & Medium pubescent & 88 & 39.5 \\
\hline & & 9 & Strongly pubescent & 14 & 6.3 \\
\hline \multirow[t]{2}{*}{4} & \multirow[t]{2}{*}{ Auricle pigmentation } & 0 & Non pigmented & 197 & 88.3 \\
\hline & & 1 & Pigmented & 26 & 11.7 \\
\hline \multirow[t]{3}{*}{5} & \multirow{3}{*}{ Leaf attitude } & 1 & Erect & 71 & 31.8 \\
\hline & & 5 & Intermediate & 73 & 32.7 \\
\hline & & 7 & Drooping & 79 & 35.4 \\
\hline III & \multicolumn{5}{|c|}{ Floral traits } \\
\hline \multirow[t]{2}{*}{6} & \multirow[t]{2}{*}{ Inflorescence pigmentation } & 0 & Non pigmented & 194 & 87.0 \\
\hline & & 1 & Pigmented & 29 & 13.0 \\
\hline \multirow[t]{2}{*}{7} & \multirow[t]{2}{*}{ Anther pigmentation } & 0 & Non pigmented & 49 & 22.0 \\
\hline & & 1 & Pigmented & 174 & 78.0 \\
\hline \multirow[t]{5}{*}{8} & \multirow[t]{5}{*}{ Inflorescence bristles } & 0 & Absent & 3 & 1.3 \\
\hline & & 1 & Very short & 40 & 17.9 \\
\hline & & 3 & Short but obvious & 5 & 2.2 \\
\hline & & 5 & Medium & 88 & 39.5 \\
\hline & & 7 & Long & 87 & 39.0 \\
\hline 9 & Inflorescence compactness & 3 & Loose & 74 & 33.2 \\
\hline & & 5 & Medium & 94 & 42.2 \\
\hline & & 7 & Compact & 49 & 22.0 \\
\hline & & 9 & Spongy & 6 & 2.7 \\
\hline 10 & Inflorescence lobes & 0 & Absent & 0 & 00.0 \\
\hline & & 3 & Short & 90 & 40.4 \\
\hline & & 7 & Long & 112 & 50.2 \\
\hline & & 9 & Large and thick & 21 & 9.4 \\
\hline 11 & Lobe compactness & 3 & Loose & 11 & 4.9 \\
\hline & & 5 & Medium & 109 & 48.9 \\
\hline & & 7 & Compact & 100 & 44.8 \\
\hline & & 9 & Spongy & 3 & 1.3 \\
\hline 12 & Inflorescence shape & 1 & Cylindrical & 209 & 93.7 \\
\hline & & 2 & Pyrimidical & 10 & 4.5 \\
\hline & & 3 & Obviate & 4 & 1.8 \\
\hline 13 & Plant pigmentation & 0 & Non pigmented & 208 & 93.3 \\
\hline & & 1 & Pigmented (Purple) & 15 & 6.7 \\
\hline 14 & Apical sterility in Panicle & 1 & Present & 90 & 40.4 \\
\hline & & 0 & Absent & 133 & 59.6 \\
\hline IV & & & Grain traits & & \\
\hline 15 & Grain colour & 1 & Red & 5 & 2.2 \\
\hline & & 2 & Black & 3 & 1.3 \\
\hline & & 3 & White & 147 & 65.9 \\
\hline & & 4 & Yellow & 68 & 30.5 \\
\hline 16 & Grain Shape & 1 & Oval & 201 & 90.1 \\
\hline & & 0 & Elliptical & 22 & 9.9 \\
\hline
\end{tabular}


Fig.1 Pie diagram depicting variability for qualitative traits among 223 foxtail millet reference set
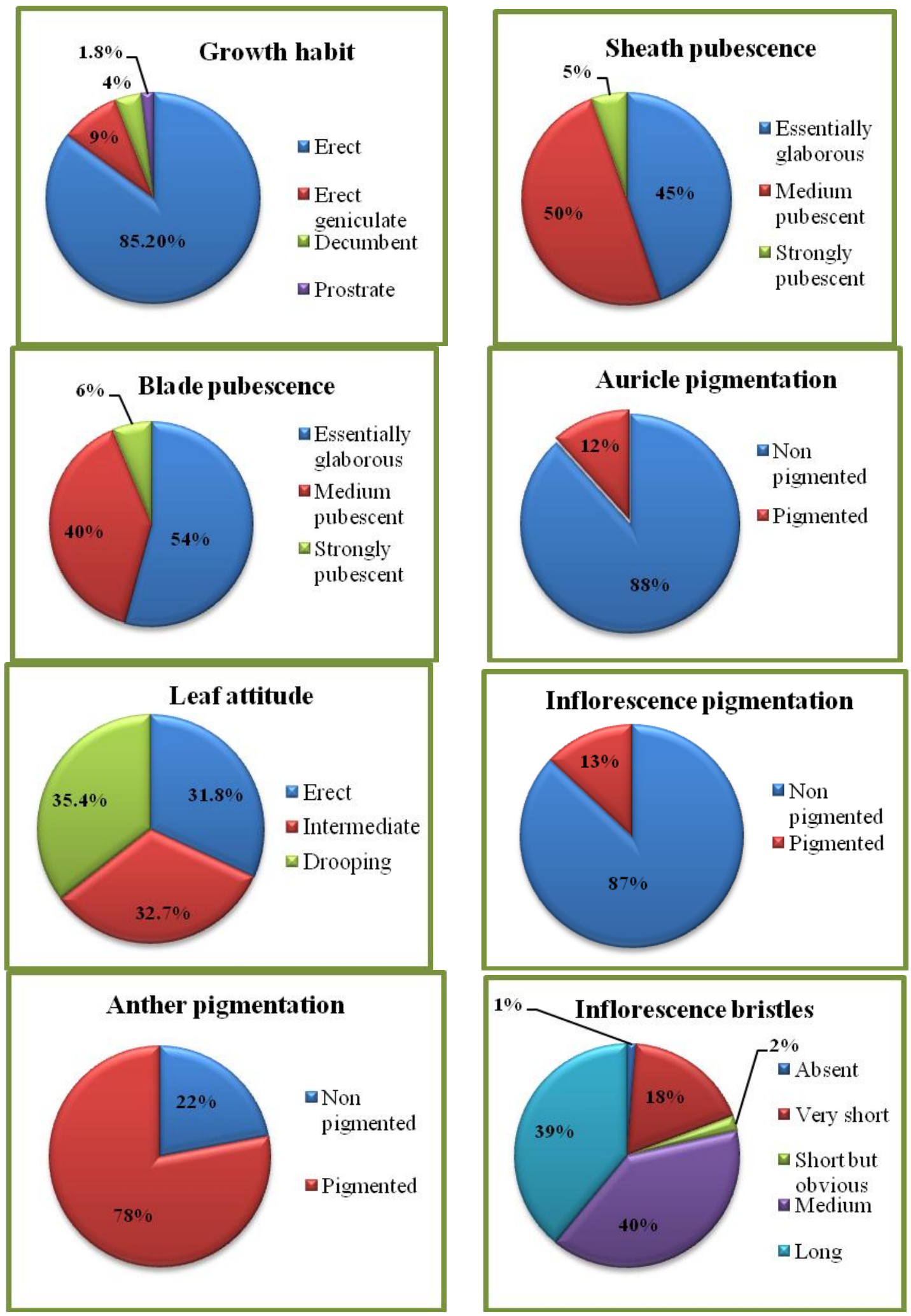

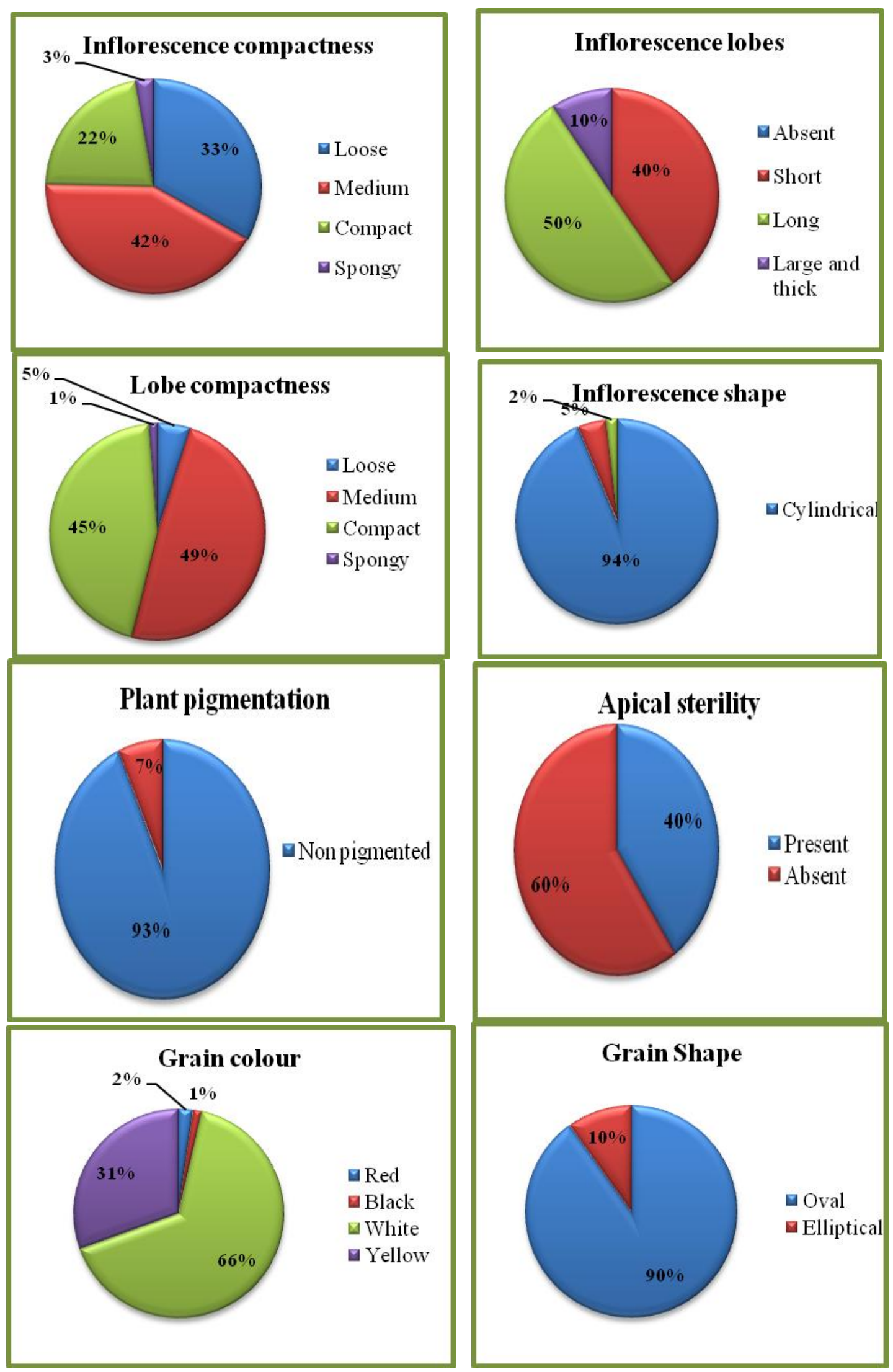
At late flowering stage, frequency of pigmented anther was predominant (174 accessions and $78 \%$ ) followed by nonpigmented anther (49 accessions and $22.0 \%$ ) indicating that high yield was associated with purple pigmentation in plant parts was reported by Shigeta (1985) in finger millet. With respect to inflorescence bristles, as many as 88 accessions (39.5\%) were medium bristles on inflorescence followed by 87 accessions (39.0\%) with long bristles, very short bristles (40 accessions and $17.9 \%$ ), short but obvious (5 accessions and $2.2 \%$ ) and 3 accessions $(1.3 \%)$ showed absence of bristles indicating that inflorescence bristles containing silica can significantly enhance insect pest resistance in plants with consequent yield increases according to Laing (2006) in poaceae family. This observation in foxtail millet is in accordance with Vetriventhan (2011). Inflorescence compactness was classified into four classes (low, medium, compact and spongy). Of which medium (94 accessions and $42.2 \%$ ) inflorescence was the most prevalent in reference set followed by loose inflorescence (74 accessions and $33.2 \%$ ), compact inflorescence (49 accessions and $22.0 \%$ ) and only 6 accessions were found to be spongy inflorescence $(2.7 \%)$. High yielding accessions in the present study possessed either compact or medium compact inflorescence and agrees with the earlier findings of Ayyangar and Rao (1932) in finger millet and Vetriventhan (2011) in foxtail millet. Among the 223 accessions, long inflorescence lobes were the most common class represented by 112 accessions $(50.2 \%)$ followed by short inflorescence lobes (90 accessions and 40.4\%) and 21 accessions were 9.4 per cent showed large and thick inflorescence, indicating long inflorescence lobes pertains to higher yield. With respect to lobe compactness, all the four classes were observed in 223 germplasm accessions viz., loose, medium, compact, and spongy. Majority of accessions (109 accessions and $48.9 \%$ ) exhibited medium lobe compactness followed by compact lobe (100 accessions and 44.8\%), loose lobe compactness (11 accessions and $4.9 \%$ ) and only 3 accessions $(1.3 \%)$ were spongy types. This report is in consonance with those of Vetriventhan (2011) suggesting medium and compacted lobes with consequent yield increase and farmers preference.

Regarding inflorescence shape majority of accessions were cylindrical (209 accessions and $93.7 \%$ ) shape followed by pyrimidical shape (10 accessions and $4.5 \%$ ) and only 4 accessions $(1.8 \%)$ represented obviate shape. Among the 223 accessions, 208 accessions (93.3\%) did not show pigmentation, while purple plant pigmentation was present in 15 accessions $(6.7 \%)$ at maturity indicating that high yield was associated with purple pigmentation in plant parts was reported by Shigeta (1985) in finger millet. This result was supported by Gopal Reddy et al., 2006 and Vetriventhan, 2011. Apical sterility was present in 90 accessions (40.4\%), whereas absent in 133 accessions (59.6\%) at maturity indicating increase in yield level.

\section{Grain traits}

Grain colour was divided into four classes (red, black, white and yellow). White colour was most common in reference set (147 accessions and $65.9 \%$ ) followed by yellow colour (68 accessions and $30.5 \%$ ), red colour (5 accessions and $2.2 \%$ ) and black colour (3 accessions and $1.3 \%$ ). Similar findings have been reported by Gopal Reddy et al., (2006) in foxtail millet. However, creamy white was in higher frequency, as this is the most favored color among the farmers.

Regarding grain shape, as many as 201 accessions (90.1\%) had oval grain shape followed by 22 accessions $(9.9 \%)$ with 
elliptical grain shape. This frequency distribution contrastingly agrees with earlier findings of Chandrashekhar Hardari, (2009)

The present studies concluded that, it could be opined from the aforesaid discussion that the germplasm accessions reported in the present investigation harbour tremendous polymorphism for several qualitative traits towards erect growth habit, medium sheath pubescence, essentially glaborous blade pubescence, non-pigmented auricle, drooping leaf attitude, non-pigmented inflorescence, pigmented anther, medium bristles on inflorescence, medium inflorescence compactness, long inflorescence lobes, medium lobe compactness, cylindrical inflorescence shape, non-pigmented plants at maturity, presence of apical sterility, white grain colour and oval grain shape score were the most predominant classes in various qualitative traits. A few of the polymorphic traits could be used as diagnostic descriptors for germplasm characterization, purity assessment and genetic studies. The accessions bearing highly compact inflorescence and pigmented types are of farmer's preference could be used as donors for developing high yielding cultivars with high farmer and consumer preference. These identified DUS traits will be used in characterization of new varieties of foxtail millet for release and registration.

\section{References}

Ayyangar, G. N. R. and Rao, K. P. 1932. Inheritance of characters in ragi (Eleusine coracana Gaertn.) Part VI: Earhead shapes. Indian J. Agric. Sci. 2: 254-265.

Chandrashekhar Hardari, B. 2009. Formation of core set in African and Indian finger millet (Eleusine coracana (L.) Gaertn) accessions. M.Sc. (Agri) Thesis, Univ. Agric. Sci. Bangalore.
Debas, B. S., Mathur, P. N. and Pareek, S. K. 1994. Collection, Characterization and maintenance of plant genetic resources of millets, arid legumes, medicinal plants and aromatic plants. Ex-situ conservation of plant genetic resources. National Bureau of Plant Genetic Resources, ICAR, New Delhi-110012. pp. 72-80.

Gopal Reddy, V., Upadhyaya, H. D. and Gowda, C. L. L. 2006. Characterization of world's foxtail millet germplasm collections for morphological traits. International Sorghum and Millets Newsletter. 47: 107-109.

Gopal Reddy, V., Upadhyaya, H. D. and Gowda, C. L. L. 2007. Morphological characterization of world's proso millet germplasm collection. ejournal. icrisat. org. 3 (1): 1-4.

Gopal Reddy, V., Upadhyaya, H. D., Gowda, C. L. L. and Sube Singh. 2009. Characterization of eastern African finger millet germplasm for qualitative and quantitative characters at ICRISAT. ejournal. icrisat. org. 7: 1-9.

IBPGR, 1985. Descriptors for Setaria italica and S. pumila, Rome. pp. 1-18.

Jagadeesh Babu, C. S., Byre Gowda, M., Girish, G., Gowda, T. K. S. 2008. Screening of Dolichos germplasm for pod borers and bruchids. Environment and Ecology. 26 (4c): 2288-2290.

Liang, M. D., Gatarayiha, M. C. and Adandonon, A. 2006. Silicon use for pest control in agriculture: A review. Proc. S. Afr. Sug. Technol. Ass. 80: 278286.

Marathee, J. P. 1993. Structure and characteristics of the world millet economy. Advances in small millet. $\mathrm{Pp}$. 159-178.

Noirot, M., Hamson, S. and Anthony, F. 1996. The principal component scoring: A new method of constituting a core 
collection using quantitative data. Genetic Resour. Crop Evol. 43: 1-6.

Project Co-Ordination Cell, 2002. Evaluation of foxtail millet Germplasm catalogue developed by AICSMIP, UAS, GKVK, Bangalore. pp. 3-5.

Rao, C. R. 1948. The utilization of multiple measurements in problems of biological classification. J. Roy. Sat. Soc. 10: 159203.

Raut, V. M. 2003. Qualitative genetics of Soyabean- a review. Soyabean Research 1:1-28.

Selvi, D., Srimathi, P., Senthil, N. and Ganesan, K. N. 2013. Distinctness, uniformity and stability (DUS) characterization on phenological traits and assessing the diversity of inbreds in maize (Zea mays L.). African. J. Agric. Res. 8 (48): 6086-6092.
Shigeta, M. 1985. The genetic diversity of finger millet (Eleusine coracana, Gaertn.) and wild finger millet (sp. africana) M.Sc. (Agri) Thesis, Kyoto University. Japan.

Smith, J. S. C., and Smith, O. S. 1992. Finger printing crop varieties. Adv. Agron. 47: $85-140$.

Upadhyaya, H. D., Yadav, D., Dronavalli, N., Gowda, C. L. L. and Singh, S. 2010. Mini core germplasm collections for infusing genetic diversity in plant breeding programs. Electron. J. Pl. Breed. 1 (4): 1294-1309.

Vetriventhan, M. 2011. Phenotypic and genotypic diversity in the foxtail millet (Setaria italica (L.) Beauv.) core collection. Ph.D. Thesis, Tamil Nadu. Agril. Univ. Coimbatore.

\section{How to cite this article:}

Harshiya Banu, Jayarame Gowda and Channabyre Gowda, M.V. 2018. Characterization and Identification of DUS Traits in Reference Set of Foxtail Millet Germplasm (Setaria italica (L.) Beauv.). Int.J.Curr.Microbiol.App.Sci. 7(12): 175-183. doi: https://doi.org/10.20546/ijcmas.2018.712.023 